\title{
Cold and transition season cloud condensation nuclei measurements in western Colorado
}

\author{
D. S. Ward ${ }^{1}$ and W. R. Cotton ${ }^{2}$ \\ ${ }^{1}$ Earth and Atmospheric Science, Cornell University, Ithaca, New York, USA \\ ${ }^{2}$ Atmospheric Science, Colorado State University, Fort Collins, Colorado, USA \\ Received: 1 November 2010 - Published in Atmos. Chem. Phys. Discuss.: 12 November 2010 \\ Revised: 7 April 2011 - Accepted: 21 April 2011 - Published: 10 May 2011
}

\begin{abstract}
Recent studies have shown that orographic precipitation and the water resources that depend on it in the Colorado Rocky Mountains are sensitive to the variability of the region's aerosols, whether emitted locally or from distant sources. However, observations of cloud droplet nucleating aerosols in western Colorado, climatologically upwind of the Colorado Rocky Mountains, have been limited to a few studies at a single, northern site. To address this knowledge gap, atmospheric aerosols were sampled at a ground site in southwestern Colorado and in low-level north to south transects of the Colorado Western Slope as part of the Inhibition of Snowfall by Pollution Aerosols (ISPA-III) field campaign. Total particle and cloud condensation nuclei (CCN) number concentrations were measured for a 24-day period in Mesa Verde National Park, in September and October 2009. Regression analysis showed a positive relationship between mid-troposphere atmospheric pressure to the west of the site and the total particle count at the ground site, but no similar statistically significant relationship was found for the observed CCN. These data were supplemented with particle and $\mathrm{CCN}$ number concentration, as well as particle size distribution measurements collected aboard the King Air platform during December 2009. A CCN closure attempt was performed and suggested that the sampled aerosol may have had a low hygroscopicity that changed little with the largescale wind direction. Together, the sampled aerosols from these field programs were characteristic of a rural continental environment with $\mathrm{CCN}$ number concentrations that varied slowly in time, and little in space along the Western Slope.
\end{abstract}

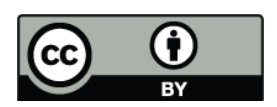

Correspondence to: D. S. Ward (dsw25@cornell.edu)

\section{Introduction}

Variations in the concentration of cloud condensation nuclei $(\mathrm{CCN})$ in the atmosphere have been shown to impact the microstructure of clouds (Andreae and Rosenfeld, 2008), leading to changes in cloud radiative properties (e.g. Twomey, 1977; Kaufman et al., 2002) and precipitation efficiency (e.g. Warner, 1968; Givati and Rosenfeld, 2004; Saleeby et al., 2009). In general, an increase in CCN number concentration results in a higher cloud droplet number concentration (CDNC) and smaller droplets compared to a cloud with similar liquid water content (LWC) but relatively fewer CCN, potentially causing numerous microphysical and dynamical feedbacks (Ramanathan et al., 2001). Since a majority of atmospheric particles originate from or are influenced by anthropogenic activities (Andreae, 2007) the CCN population is an essential element in our understanding of the human impacts on clouds, which modulate regional and global climate (Charlson et al., 2001; Ghan and Schwartz, 2007). Despite numerous studies on this topic, there is considerable uncertainty regarding the effect of anthropogenic aerosols on global precipitation. Global climate model simulations in general predict that increasing aerosols has suppressed precipitation globally (Levin and Cotton, 2009). However, Zhang et al. (2007) reported that precipitation increased in the Northern Hemisphere mid-latitudes during the latter half of the 20th century, suggesting that the role of anthropogenic aerosols is poorly understood. In fact, the magnitude and even the sign of the feedbacks of aerosols on clouds and precipitation depend on the cloud regime being affected and in many cases are not well known (Stevens and Feingold, 2009), making studies of CCN variability important on local and regional scales.

Previous studies show that orographic clouds are particularly susceptible to aerosol effects (Levin and Cotton, 2009). In mixed-phase orographic clouds, where ice crystals co-exist with water droplets, a decrease in the size of

Published by Copernicus Publications on behalf of the European Geosciences Union. 
supercooled cloud droplets reduces the riming efficiency which may lead to a decrease in the liquid water content of precipitation falling as snow or a change in the spatial distribution of the precipitation (Borys et al., 2003; Saleeby et al., 2009). Investigations of precipitation climatology in mountainous regions in the western US have demonstrated a longterm decrease in accumulated precipitation downwind and upslope of urban areas (Givati and Rosenfeld, 2004; Rosenfeld and Givati, 2006). Jirak and Cotton (2006) found similar results along the Colorado Front Range, attributing the lower precipitation to increases in pollution from the urban corridor. Case studies of mixed-phase orographic clouds have also shown a connection between lower precipitation production and local anthropogenic aerosol sources (Borys et al., 2000, 2003), and recent modeling studies of these clouds by Lynn et al. (2007) and Saleeby et al. (2009) have demonstrated sensitivity in the precipitation fields to changes in $\mathrm{CCN}$ number concentration $\left(N_{\mathrm{ccn}}\right)$.

Issues of orographic precipitation modification are of particular significance in western Colorado where water supplies depend largely on the snow produced by orographic clouds (Saleeby et al., 2009). The sharp rise in elevation from west to east along Colorado's Western Slope leads to frequent formation of precipitating orographic clouds. This, in combination with the location of an aerosol and cloud microphysics observing station in the northern Colorado Park Range, makes the Western Slope region an ideal laboratory for studying aerosol-orographic cloud interactions. In fact, a substantial portion of the data on this topic has been collected in northwestern Colorado and southeastern Wyoming.

While the observational evidence supports a potentially important aerosol impact on orographic clouds in western Colorado (Borys et al., 2003), the scope of the impact remains largely unknown. For example, it has been hypothesized that precipitation from high LWC mixed-phase orographic clouds may be more sensitive to increases in aerosol because of the greater potential for riming compared to low LWC clouds that contain more ice (Borys et al., 2000). High LWC clouds are more common in southwest Colorado than in northwest Colorado and, thus, may be more susceptible to decreases in riming efficiency due to increases in $N_{\text {ccn }}$. However, observational records of droplet-nucleating aerosol do not exist for the majority of the Western Slope. A few studies have measured $\mathrm{CCN}$ at the northern end of this region and in southern Wyoming (e.g. Saleeby and Cotton, 2009; Politovich and Vali, 1983; Delene and Deshler, 2001) but to our knowledge no measurements of $N_{\mathrm{ccn}}$ have ever been published for the central Colorado Western Slope leaving a gap in our understanding of aerosol/cloud interactions in a region that is potentially sensitive to $N_{\mathrm{ccn}}$ variations.

In this study, atmospheric aerosols were sampled in southwestern Colorado and along the length of the Western Slope. The cloud active portion, that is the fraction of the aerosol population that will nucleate a cloud droplet for given conditions, was measured at fixed supersaturations. Data were

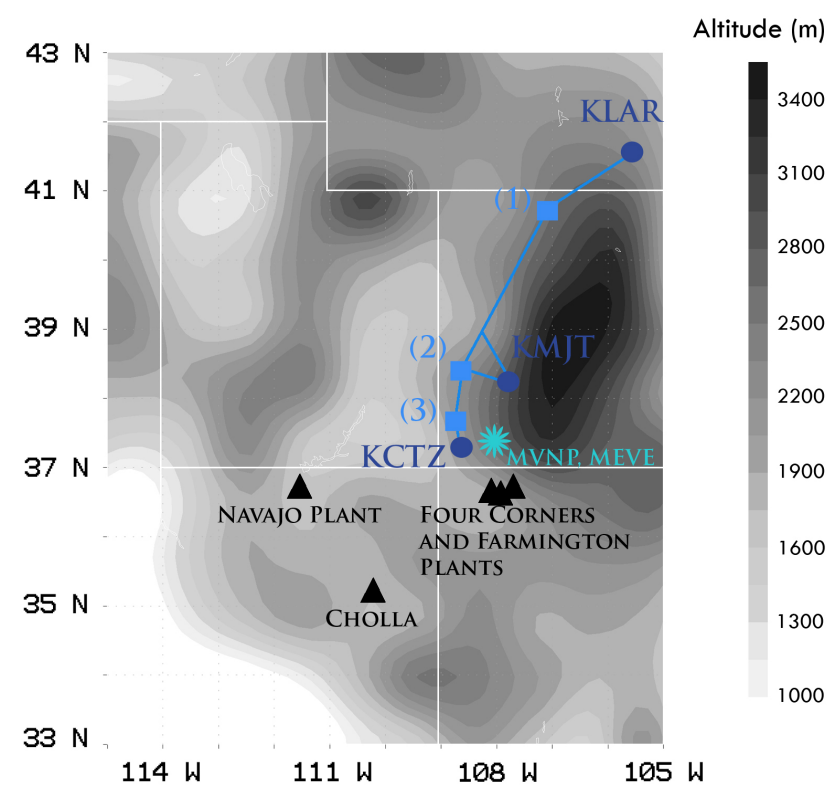

Fig. 1. Detail map of the western United States centered on the Colorado Western Slope. Topography is contoured. The location of the Mesa Verde field site is indicated with a teal star. King Air flight tracks are shown in light blue and the vertical stack locations are given by squares. The vertical stack locations are (1) Steamboat Springs, (2) Nucla, and (3) Cortez. Several local coal-fired power stations are marked with black triangles.

collected as part of the 2009-2010 Inhibition of Snowfall by Pollution Aerosols (ISPA)-III field campaign in western Colorado. The goals of this paper are to (1) establish $N_{\mathrm{ccn}}$ datasets for fall and winter in this region, (2) identify the location of possible sources of the observed CCN, (3) report on the bulk hygroscopicity of Western Slope aerosols and (4) point out the limitations of the applied methods to guide future research.

\section{Mesa Verde observations}

Mesa Verde National Park (MVNP) was chosen as the southwestern Colorado sampling site for this phase of the ISPA-III project. The site is located to the southwest of the higher elevations in the San Juan Mountains at an elevation of $2190 \mathrm{~m}$ a.m.s.l. Figure 1 shows the location of the sampling site with reference to the surrounding topography. The local ecosystem consists mainly of juniper and pinyon pine trees and the topsoil contains loess, a fine, red-colored silt. It is a location that endures frequent forest fires especially during the summer, although none burned in the vicinity during this project.

Mesa Verde is located in a region of low population density and the typical airmass in the region is of continental origin (Hobbs et al., 1980). The main local industry is agriculture. Most of the agricultural activity takes place in small 
areas to the north of MVNP and to the east in the Mancos River Valley. Despite the rural setting, there are several large point sources of particles and gas-phase particle precursors that are local to the observation site. The most important of these, potentially, is the Four Corners power plant located about $100 \mathrm{~km}$ south-southeast of Mesa Verde (Fig. 1). Together with two additional power plants positioned between the Four Corners plant and Mesa Verde, these sources are responsible for $\mathrm{SO}_{2}$ emissions in excess of 10 tons per day on average and the emission of large amounts of $\mathrm{NO}_{\mathrm{x}}$ (US EPA, 2009). Decreased visibility was often observed in the direction of these sources, which stand at a lower altitude than the sampling site. Other substantial power plant aerosol sources, the Navajo and Cholla plants, are located to the west and southwest of Mesa Verde but are more distant than Four Corners.

The sampling site is co-located with the Interagency Monitoring of Protected Visual Environments (IMPROVE) network collection site MEVE (Fig. 1). Atmospheric aerosol samples are collected at IMPROVE sites on four separate filters for $24 \mathrm{~h}$ periods once every three days. The mass ratios of collected particulate species are determined by several different analysis techniques (Hyslop and White, 2008). It is important to note that sulfate and nitrate aerosol are assumed to exist as ammonium sulfate and ammonium nitrate and their mass is not measured as separate from ammonium. Also, these data do not provide information about particle number concentration. Here, IMPROVE data will be used only to gain a general sense of the long-term total aerosol mass concentration and composition of particles with diameters less than $2.5 \mu \mathrm{m}\left(\mathrm{PM}_{2.5}\right)$.

Figure 2 shows the contribution to total $\mathrm{PM}_{2.5}$ by IMPROVE estimated species at MEVE averaged from 19992008 for the dates of the ISPA-III observations. The IMPROVE samples are collected for one day out of every three days, but the sampling date is not the same from year to year. To reconcile this, three-day periods were defined that would each contain one sampling day from each year. The averages are for the three-day period centered on the date shown in the figure. For example, the 18 September average represents samples collected on 17,18 , or 19 September. The average aerosol mass concentration for this location was about $3 \mu \mathrm{g} \mathrm{m}^{-3}$ during the September-October time period making MEVE one of the cleaner locations in the network, but typical for a site in the Rocky Mountains (Debell, 2006). Similar sulfate and organic aerosol mass are evident in Fig. 2 with only small contributions from nitrate aerosol and elemental carbon.

\subsection{Methods}

Two instruments were deployed to sample aerosols at MVNP: a Droplet Measurement Technologies (DMT) CCN100 instrument and a TSI 3010 condensation particle counter (CPC). These were setup inside a climate controlled build-

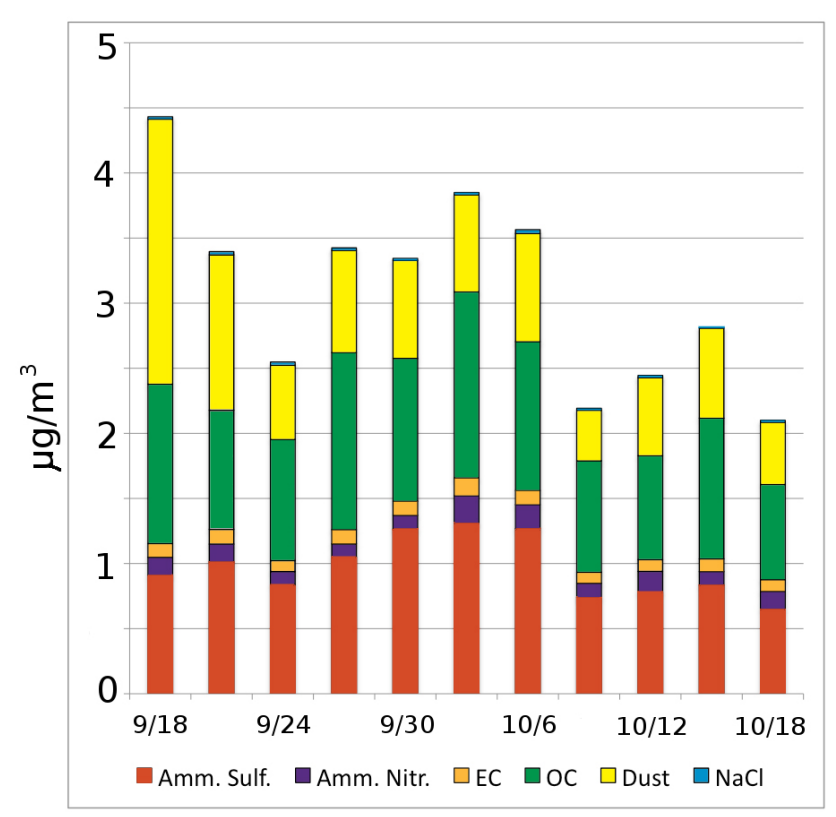

Fig. 2. $\mathrm{PM}_{2.5}$ composition as measured by the IMPROVE program at the MEVE1 site and averaged over the ten year period, 19992008. $\mathrm{EC}=$ elemental carbon; $\mathrm{OC}=$ organic carbon.

ing at the Mesa Verde Research Center. An inlet was installed on the building solely as an intake for the CCN-100 and CPC. The main inlet was constructed out of $4^{\prime \prime}$ diameter aluminum tubing with a sheltered opening at a height of $4.15 \mathrm{~m}$ above the ground and $3.1 \mathrm{~m}$ above the CCN-100 inlet manifold. At the bottom of the main inlet a fan was installed to maintain flow from the top of the tubing. Flow was directed from the main inlet to each instrument by a combination of $0.3 \mathrm{~m} \mathrm{3/8^{ \prime \prime }}$ copper tubing and flexible $12 \mathrm{~mm}$ (outside diameter) tubing (0.4 $\mathrm{m}$ for $\mathrm{CCN}-100,0.7 \mathrm{~m}$ for $\mathrm{CPC})$. The copper tubing is used to navigate the necessary change in flow direction from vertical (main inlet) to horizontal (inlet manifolds on the CCN-100 and CPC). To diminish the loss of particles by impaction on the tubing walls the copper tubing was bent only slightly in two locations and the remainder of the required $90^{\circ}$ turn was accomplished with the flexible tubing. The access opening of the copper tubing was tapered. The instrument shed was collocated with a meteorological observation tower that recorded wind speed and direction, temperature, dewpoint temperature, solar radiation, and precipitation.

The DMT CCN-100 is a continuous-flow instrument that creates a controlled supersaturated environment within which particles can grow to droplet size. It was developed by Roberts and Nenes (2005) and has been used in many field programs and laboratory studies since its introduction (e.g. Medina et al, 2007; Petters et al., 2007; Ervens et al., 2007; Cubison et al., 2008; Quinn et al., 2008; Gunthe et al., 2009). Supersaturation (SS) is maintained in the CCN-100 
by imposing a tightly controlled temperature gradient on the sheath/sample flow within a moist growth chamber. The SS produced is not constant within the growth chamber but reaches a maximum in the center. The maximum SS value achieved is considered the instrument sampling SS. While the flow rates are kept constant the SS can be set higher or lower by increasing or decreasing the temperature gradient. Particles enter the growth chamber at slightly above the ambient temperature, flow up the temperature gradient through the supersaturated environment in the center of the chamber and either reach stable equilibrium or grow into cloud droplet size. An optical particle counter (OPC) detects droplets that have reached a threshold size and reports these as CCN. The threshold droplet diameter was set to $2 \mu \mathrm{m}$ for the ISPAIII measurements. There is a risk at this size that a few of the smallest particles will activate but not have time to reach the threshold at the SS settings that were used (Roberts and Nenes, 2005). The decision to use $2 \mu \mathrm{m}$ was made to ensure consistency between this dataset and previously collected datasets at Storm Peak Lab (SPL) in northwestern Colorado. The CCN-100 was operated at a 10:1 sheath to sample flow ratio and at two values of SS: $0.3 \%$ and $0.5 \%$. It was set to alternate between the two SS settings every 15 minutes, running continuously for the entire project period taking one measurement per second. Therefore, $\mathrm{CCN}-100$ measures the subset of atmospheric aerosols that will activate cloud droplets, i.e. the cloud-active subset, at SS that are likely found in potential downwind orographic clouds. $N_{\mathrm{ccn}}$ is reported at the ambient pressure and instrument temperature.

The CCN-100 used at Mesa Verde was calibrated on 9/14/09 at the DMT facility in Boulder, Colorado. The SS in the instrument is calibrated by sampling a distribution of particles for which the CCN activity is known, usually ammonium sulfate. The instrument-set SS is then compared to the theoretically determined SS and adjusted for accuracy. Instrument uncertainty regarding $N_{\mathrm{ccn}}$ measurements is considered less than $10 \%$ for the conditions expected during this project, and uncertainty in the SS instrument setting has been reported as less than $1 \%$ (Roberts and Nenes, as cited by Quinn et al., 2008). Rose et al. (2008) estimate the uncertainty in the DMT CCN-100 SS, represented as the observed standard deviation from their experiments, as $\pm 5 \%$ of the instrument SS setting when used in the field.

The CPC detects total particle number concentration $\left(N_{\mathrm{cn}}\right)$ in a similar way. The sample flow passes through a region in the instrument that is saturated with butanol vapor and then down a temperature gradient to cause the vapor to condense onto the particles. The resulting droplets are counted by an OPC and divided by the flow volume to compute a particle number concentration. It was shown by Mertes et al. (1995) that the lower detection limit of the CPC could be decreased to diameter $(D)=5 \mathrm{~nm}$ particles by increasing the temperature difference between the saturation and condensation regions. This detection limit is defined as the diameter at which
$50 \%$ of the particles will activate and become detectable. At Mesa Verde, the CPC was run with the recommended temperature differential which results in a lower detection limit of approximately $D=10 \mathrm{~nm}$.

\subsection{Mesa Verde results}

The high-frequency data (one observation per second for the $\mathrm{CCN}-100$ and CPC, but recorded every $10 \mathrm{~s}$ for the CPC) were smoothed using a $30 \mathrm{~min}$ running average. Note that a $30 \mathrm{~min}$ average of the $N_{\text {ccn }}$ at a specific SS includes only $15 \mathrm{~min}$ of data because of the instrument SS cycling. For this averaging an assumption is made that the $\mathrm{CCN}-100$ is sampling similar ambient air during the $30 \mathrm{~min}$ when the instrument cycles once through each SS. Data that met certain criteria were flagged and set as missing. This was done any time the temperature gradient in the $\mathrm{CCN}-100$ was not stabilized, which occurs between every change in instrument SS and sometimes lasts between 1-2 min. Other flagging criteria, including sharp changes in the air pressure and a significant change in the flow rate through either instrument, were not encountered. An attempt was made to eliminate observations that may have been contaminated by exhaust from nearby vehicles. Surges in $N_{\text {cn }}$ that exceeded five standard deviations from the mean (computed from the $24 \mathrm{~h}$ period in question, midnight to midnight) and lasted less than two minutes were removed from the dataset. Thirteen such events were identified, all occurring between the hours of 7:55 a.m. and 5:00 p.m. LT and all on weekdays. Corresponding CCN observations were also disregarded, although the surges in that dataset were not as extreme.

Figure $3 \mathrm{~b}$ shows the time series of $N_{\mathrm{ccn}}$ at both SS values for the entire project. The average $N_{\mathrm{ccn}}$ at $\mathrm{SS}=0.3 \%$ was $302 \mathrm{~cm}^{-3}$ and at SS $=0.5 \%$ was $481 \mathrm{~cm}^{-3}$ (Table 1 ). Episodes of comparable values of $N_{\mathrm{ccn}}$ that lasted for one to several days are evident in the time series. The $N_{\mathrm{cn}}$, shown in Fig. 3a, appears to vary on much shorter timescales. To further this comparison, the lag autocorrelations of each time series are given in Table 1 . The $N_{\text {ccn }}$ time series exhibits a high autocorrelation, especially relative to that for the $N_{\mathrm{cn}}$ time series. According to VanReken et al. (2003) this is an indication that the largest particle number variations in time occur for particles that are too small to activate droplets at the prescribed SS.

A direct comparison of the observed $\mathrm{CN}$ and $\mathrm{CCN}$ is given by the activated fraction (see Table 1). The average values of activated fraction are well below 0.5 , indicating that the majority of particles counted by the CPC are too small to activate at the instrument SS. These values for activated fraction compare well to observations of, presumably, aged continental aerosols collected by Gunthe et al. (2009) in the Amazon rain forest. In contrast, Bougiatioti et al. (2009) found activated fraction values well above 0.5 even at $\mathrm{SS}=0.4 \%$. They sampled at a marine location where the aerosol is likely to be larger and consist principally of sea-salt. 
Table 1. Statistical information for physical quantities observed at MVNP. These represent the entire time series from 9/22-10/16. Lag quantities are autocorrelations for lags of 1,10 and $24 \mathrm{~h}$. The effective sample size, $n^{\prime}$, is computed using Eq. (1). Labels are as follows: $\mathrm{CCN} 3=N_{\mathrm{ccn}}(\mathrm{SS}=0.3 \%) ; \mathrm{CCN} 5=N_{\mathrm{ccn}}(\mathrm{SS}=0.5 \%) ; \mathrm{ACT} 3=N_{\mathrm{ccn}}(\mathrm{SS}=0.3 \%) / N_{\mathrm{cn}} ; \mathrm{ACT} 5=N_{\mathrm{ccn}}(\mathrm{SS}=0.5 \%) / N_{\mathrm{cn}} ;$ and C5/C3 $=N_{\mathrm{ccn}}$ $(\mathrm{SS}=0.5 \%) / N_{\mathrm{ccn}}(\mathrm{SS}=0.3 \%)$.

\begin{tabular}{lcrrrrrrrr}
\hline & Units & Mean & Min & Max & StDv & Lag 1 & Lag 10 & Lag 24 & $n^{\prime}$ \\
\hline Temp & ${ }^{\circ} \mathrm{C}$ & 54 & 31 & 82 & 10.6 & 0.96 & 0.06 & 0.74 & 11 \\
Dpt & ${ }^{\circ} \mathrm{C}$ & 22 & -5 & 48 & 10.5 & 0.96 & 0.63 & 0.26 & 11 \\
RH & $\%$ & 32 & 9 & 98 & 16.9 & 0.95 & 0.26 & 0.46 & 14 \\
Wind & $\mathrm{mph}$ & 6 & 1 & 16 & 2.8 & 0.77 & 0.11 & 0.27 & 74 \\
$N_{\mathrm{cn}}$ & $\mathrm{cm}^{-3}$ & 1773 & 336 & 10944 & 1427 & 0.94 & 0.25 & 0.07 & 33 \\
CCN3 & $\mathrm{cm}^{-3}$ & 302 & 72 & 631 & 128 & 0.98 & 0.78 & 0.61 & 10 \\
CCN5 & $\mathrm{cm}^{-3}$ & 481 & 123 & 1090 & 204 & 0.98 & 0.75 & 0.57 & 10 \\
C5/C3 & - & 1.6 & 1.14 & 2.38 & 0.17 & 0.84 & 0.45 & 0.22 & 10 \\
ACT3 & - & 0.23 & 0.01 & 0.72 & 0.14 & 0.95 & 0.58 & 0.44 & 32 \\
ACT5 & - & 0.37 & 0.02 & 0.97 & 0.21 & 0.95 & 0.60 & 0.51 & 28 \\
\hline
\end{tabular}
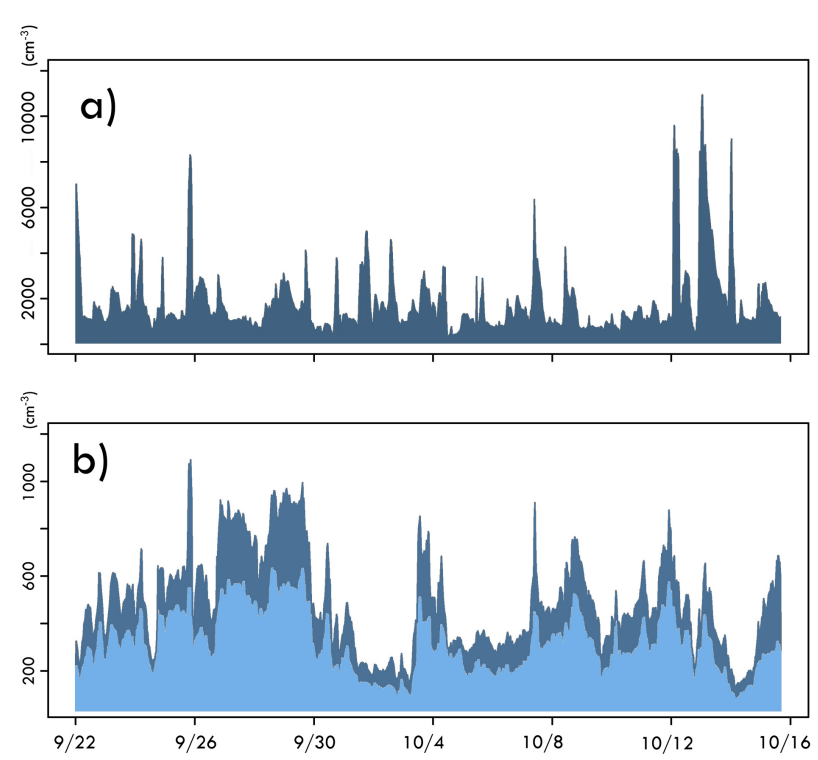

Fig. 3. Time series of (a) $N_{\mathrm{cn}}$ and (b) $N_{\mathrm{ccn}}\left(N_{\mathrm{ccn}}\right.$ at $\mathrm{SS}=0.3 \%$ shown in light blue, $N_{\mathrm{ccn}}$ at $\mathrm{SS}=05 \%$ shown in dark blue) observed at MVNP during the ISPA field project.

\subsection{Aerosol and geopotential height regression analysis}

Previous research shows that differences in the observed regional meteorology can explain some of the variability in aerosol properties observed on board aircraft or at surface sites (e.g. VanReken et al., 2003; Medina et al., 2007; Quinn et al., 2008; Furutani et al., 2008; Bougiatioti et al., 2009). Traditionally these distinctions are made using trajectory analysis and are often limited to labeling observations as marine-source or continental-source, as in VanReken et al. (2003), Furutani et al. (2008), and Bougiatioti et al. (2009). Moreover, it is difficult to test whether the relationship between the computed trajectories and observed aerosols would apply generally to future cases. In this section regression analysis will be used to investigate a more broadly applicable relationship between the large-scale wind and MVNP CCN and $\mathrm{CN}$ number concentrations.

The $700 \mathrm{mb}$ and $500 \mathrm{mb}$ geopotential height fields from the North American Regional Reanalysis (NARR) dataset (Mesinger et al., 2006) were used to represent the large-scale wind in this analysis. NARR data are output on a $349 \mathrm{x}$ by 277 y polar-stereographic grid with a horizontal grid spacing of about $32 \mathrm{~km}$ in the lower latitudes. The data are available in $3 \mathrm{~h}$ increments. Output from 9/23/09 00:00 GMT to 10/16/09 00:00 GMT was used to construct the time series of the geopotential height fields.

The $700 \mathrm{mb}$ and $500 \mathrm{mb}$ geopotential height fields were weighted by the cosine of the latitude. This equalizes the influence of each grid point on the basis of grid-box area. The $24 \mathrm{~h}$ time mean was removed from all grid points. Missing data were removed from the dataset before analysis. Next, the time series of $N_{\mathrm{cn}}$ and $N_{\mathrm{ccn}}$ from MVNP were averaged over $3 \mathrm{~h}$ time periods, centered on the corresponding NARR output time. The time series were standardized and the $24 \mathrm{~h}$ time mean was removed from each. Then, the $500 \mathrm{mb}$ and $700 \mathrm{mb}$ geopotential height time series were regressed onto the time series of $N_{\mathrm{ccn}}$ and $N_{\mathrm{cn}}$. The resulting regression maps were plotted and the correlations at each grid point were computed. The correlations are used to test whether the regression relationship is significant and could be applied to cases outside of the ISPA-III observation period, or if the relationship is specific to this case and not representative of the potential population of regression coefficients at each grid point. The latter is the null hypothesis. The correlations were checked for significance against the null hypothesis using a two-tailed student $t$ test. An effective sample size was calculated for the test using equation 5.12 from Wilks (1995):

$n^{\prime} \cong n \frac{1-\rho_{1}}{1+\rho_{1}}$ 
where $\rho_{1}$ is the lag-1 autocorrelation coefficient, $n$ is the sample size and $n^{\prime}$ is the effective sample size, or the equivalent number of independent samples. The effective sample size corrects for the persistence in the $\mathrm{CCN}$ dataset. The high persistence in the $\mathrm{CCN}$ datasets, given by the autocorrelations in Table 1, reduces the effective sample size to 10 . The result is the same when $n^{\prime}$ is computed using the lag-1 autocorrelation for the $3 \mathrm{~h}$ standardized dataset. The $N_{\mathrm{cn}}$ series varies on a shorter timescale and, therefore, has a higher effective sample size, $n^{\prime}=33$. This is reduced in the regression analysis to one independent sample per day $\left(n^{\prime}=23\right)$, the assumed sample size for the NARR datasets. Significance was tested at the $95 \%$ confidence level.

Figure 4a shows the regression of the $500 \mathrm{mb}$ height field onto the $N_{\text {ccn }}(\mathrm{SS}=0.3 \%)$ time series. This is the pattern of $500 \mathrm{mb}$ heights that explains the most variance in the $N_{\text {ccn }}(\mathrm{SS}=0.3 \%)$ time series. The pattern includes positive regression coefficients over the central and western United States, as well as over the northern Pacific. High (low) pressure in these regions was associated with high (low) $N_{\mathrm{ccn}}$ at MVNP during this project. The dashed line indicates areas that would be statistically significant for an effective sample size of $n^{\prime}=23$, or one independent sample per day. None of the regression coefficients were statistically significant at the $95 \%$ confidence level using the computed $n^{\prime}=10$. This indicates that the height pattern in Fig. 4a may express the influence of one or more specific events. Therefore it would not be appropriate to extend conclusions drawn from these data to future cases.

The pattern is similar for the regression of $500 \mathrm{mb}$ height onto $N_{\mathrm{ccn}}(\mathrm{SS}=0.5 \%)$ and for $700 \mathrm{mb}$ height onto $N_{\mathrm{ccn}}$ at both values of SS (not shown). However, the regression onto the $N_{\mathrm{cn}}$ time series (Fig. 4b) results in a region of negative regression coefficients off the west coast of the United States of which a large portion is statistically significant at a $95 \%$ confidence level. This pattern, with negative regression coefficients to the west and positive to the east suggest that high pressure off the coast of western United States and a weak trough over the intermountain west is related to low $N_{\text {cn }}$ at MVNP. The increased likelihood of wet deposition of aerosols from precipitation under low pressure both locally and to the west of MVNP could reduce $N_{\mathrm{cn}}$ at MVNP. However, very little precipitation was observed at MVNP $\left(0.65^{\prime \prime}\right)$ or in the intermountain west during this field study making this explanation difficult to substantiate.

Contributions to the regression pattern in Fig. $4 \mathrm{~b}$ could alternatively have been made by a strong low in the northeast Pacific coupled with a weak ridge of high pressure over the central US that led to increased $N_{\text {cn }}$ at MVNP. High pressure is most often associated with a stable airmass, increased solar radiation at the surface and light winds. These airmass characteristics will tend to increase aerosol aging and reduce long-range transport, enhancing the impact of local aerosols sources. The emissions from the sources near MVNP (Fig. 1) could have contributed to the increased $N_{\mathrm{cn}}$ under this sce-
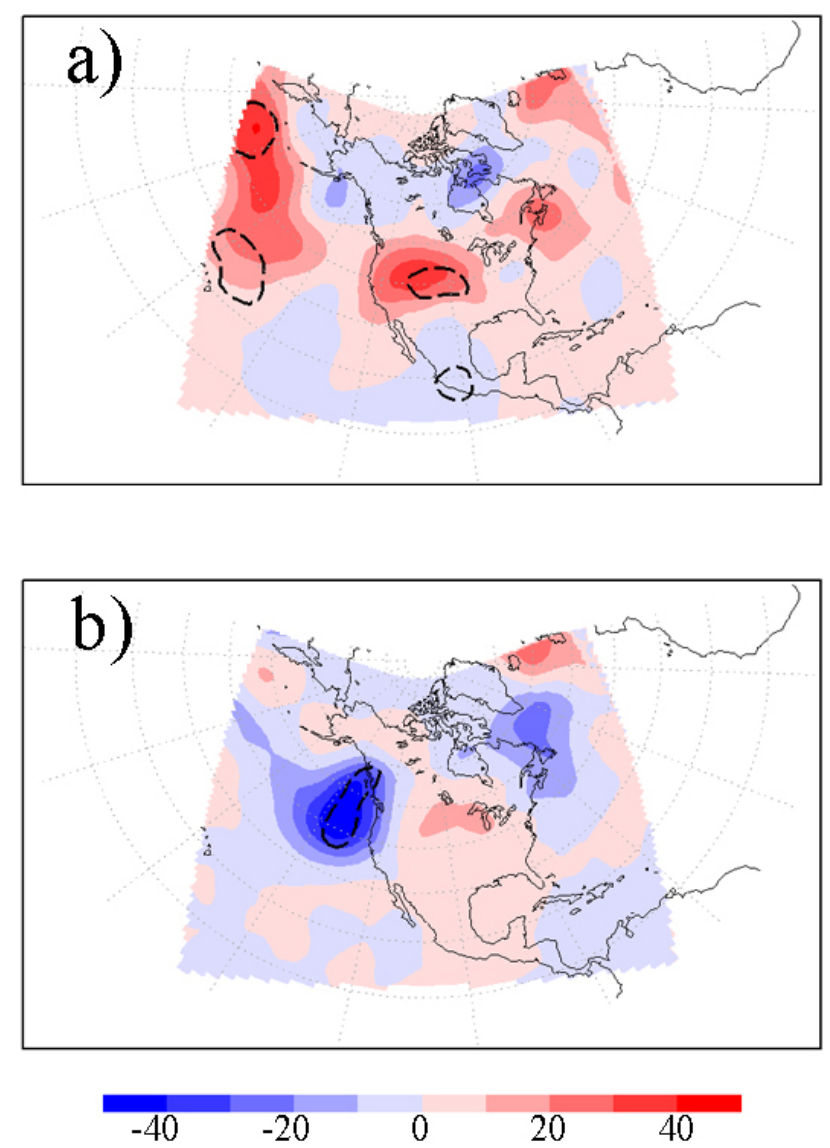

Fig. 4. Regression of $500 \mathrm{mb}$ geopotential height onto the time series of (a) $N_{\text {ccn }}$ sampled at MVNP with $\mathrm{SS}=0.3 \%$ and (b) $N_{\text {cn }}$. Units are geopotential meters (gpm) per standard deviation of (a) $N_{\text {ccn }}$ and (b) $N_{\mathrm{cn}}$. Regions where the correlation between (a) $N_{\mathrm{ccn}}$ or (b) $N_{\mathrm{cn}}$ and height is significant at the $95 \%$ confidence level assuming $n^{\prime}=23$ are outlined with a dashed line.

nario. The relationship between increased $N_{\text {ccn }}$ and high pressure in the western US (Fig. 4a) also supports this idea.

The regression maps in Fig. 4 suggest that $500 \mathrm{mb}$ winds from the east were associated with high $N_{\mathrm{ccn}}$ at MVNP and weak southerly winds were associated with high $N_{\mathrm{cn}}$. To test whether these signals appear in the surface winds at MVNP, $N_{\text {ccn }}$ and $N_{\text {cn }}$ data were binned by the corresponding surface wind direction observed at MVNP. The average $N_{\text {ccn }}$ and activated fraction for four different wind directions are given in Fig. 5a and b, respectively. The four bins cover the entire 360-degree compass rose with each bin centered on the direction shown in Fig. 5. The differences between the plotted means are not statistically significant. The highest average $N_{\text {ccn }}$ was observed with a southeasterly surface wind, as was the lowest average activated fraction (meaning the highest $N_{\mathrm{cn}}$ values were also associated with the southeast wind). This could be evidence that airmasses containing numerous particles from the power plant sources to the south 


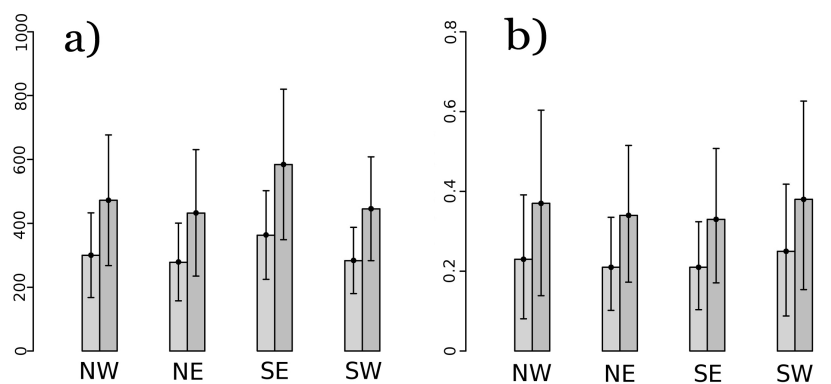

Fig. 5. Mean (a) $N_{\mathrm{ccn}}\left(\mathrm{cm}^{-3}\right)$ and (b) activated fraction for different surface wind directions observed at the MVNP site. Light grey indicates data for $\mathrm{SS}=0.3 \%$ and dark grey for $\mathrm{SS}=0.5 \%$. The error bars show one standard deviation above and below the mean.

and southeast of MVNP were transported to the site. Freshly emitted particles are likely to be small and may act to decrease the activated fraction (Medina et al., 2007).

\subsection{Discussion}

CCN number concentration data were collected with a DMT $\mathrm{CCN}-100$ at a site in MVNP. These were supplemented with $N_{\text {cn }}$ and meteorological data, all measured continuously for a period of 24 days. The $N_{\mathrm{ccn}}$ observations varied within a range of about one order of magnitude and rarely exceeded $1000 \mathrm{~cm}^{-3}$ at $\mathrm{SS}=0.5 \%$. The average $N_{\mathrm{ccn}}$ at the surface site was $302 \mathrm{~cm}^{-3}$ at SS $=0.3 \%$ and $481 \mathrm{~cm}^{-3}$ at $\mathrm{SS}=0.5 \%$. These values show that the MVNP environment is clean when compared to observations in the northeastern and southeastern United States that typically average 2-3 times greater than the MVNP measurements (Medina et al., 2007; Ervens et al., 2007; Hudson, 2007; Quinn et al., 2008). The $N_{\text {ccn }}$ observations at MVNP were remarkably episodic, with high or low events lasting for one to several days.

The MVNP measurements are comparable in magnitude to $N_{\mathrm{cn}}$ and $N_{\mathrm{ccn}}$ at SPL collected in January and February of 2007 as reported by Saleeby et al. (2009) and Ward et al. (2010). The $N_{\text {ccn }}$ observed at MVNP is on average somewhat higher, although this is not unexpected given the difference in seasons. Also, SPL should be expected to be somewhat cleaner because of its high altitude and frequent disconnection from the surface layer below. The MVNP aerosol may be considered, by geographic proximity to SPL, to also be characteristic of rural continental airmasses, although typically size distribution information would be used to make this distinction. CDNC and CCN at Elk Mountain in southern Wyoming during January and April were found to be between 100 to $300 \mathrm{~cm}^{-3}$ for SS estimated to be between $0.4 \%$ to $0.65 \%$ using the Twomey (1959) power law equation for CCN concentration spectra (Politovich and Vali, 1983). Eltgroth and Hobbs (1979) measured ambient $N_{\mathrm{cn}}$ in excess of $3500 \mathrm{~cm}^{-3}$ on three separate days in northern New Mexico.
Although, they sampled air closer to the Four Corners power plant and these observations are more than 30 years old.

At MVNP in 2009, it is unclear whether the large, local aerosol sources impacted the measurements of $N_{\mathrm{ccn}}$ and $N_{\mathrm{cn}}$. Observed spikes in $N_{\mathrm{cn}}$ were not always accompanied by similar spikes in $N_{\text {ccn }}$. This could be evidence of the influence of a nearby combustion source introducing a large number of small particles into the environment (Medina et al., 2007), or producing enough $\mathrm{SO}_{2}$ to bring about an aerosol nucleation event in the area.

\section{King Air observations}

CCN data have been collected in northwestern Colorado at SPL (Saleeby et al., 2009), and nearby at Elk Mountain (Politovich and Vali, 1983), and now in southwestern Colorado (see Sect. 2). About $350 \mathrm{~km}$ separate these sites from north to south, a stretch through which much of the aerosols in the central Rocky Mountains of Colorado will pass on the prevailing westerlies that are common to the region. In December of 2009, sixteen low-altitude transects of this region, also known as the Western Slope, were made during eight flights from Laramie, WY to Cortez and Montrose, CO. Vertical profiles were carried out at the northern and southern ends of transects near SPL and Cortez, CO. On-board measurements of $N_{\mathrm{cn}}$, aerosol size distribution, and $N_{\mathrm{ccn}}$ at three different values of SS were made on all transects.

\subsection{The King Air observational platform}

The King Air is a twin-propeller turboprop aircraft operated by the University of Wyoming in Laramie, WY, for tropospheric research. On-board instruments measure cloud physics parameters, atmospheric radiation and atmospheric state quantities. For the ISPA flights the main interest was sampling of aerosols and their CCN activity. For this reason a CPC was operated aboard the aircraft as well as a Particle Measuring Systems passive cavity aerosol spectrometer probe (PCASP) for differentiating particle sizes and a staticdiffusion, thermal-gradient $\mathrm{CCN}$ instrument.

\subsubsection{Instruments and calibration}

The University of Wyoming (UWYO) CCNC-100A measures $N_{\text {ccn }}$ by introducing ambient aerosols to an environment that is supersaturated with respect to water and detecting the particles that activate droplets. The instrument itself consists of a chamber that is circular in the horizontal dimension with ports for sample intake and exhaust, a temperaturecontrolled plate on the chamber bottom, and a photodetector. The theory and operation of this instrument is described by Delene and Deshler (2000), Snider et al. (2003), and Snider et al. (2006). The method for creating a supersaturated environment in the CCNC-100A is similar to that for the DMT 
continuous flow diffusion chamber in that a sharp temperature gradient across a small space is used to establish and control the SS. In the CCNC-100A, aerosols are admitted into the chamber, where they are sealed off from the flow and exposed to the supersaturated environment controlled by the temperature gradient. Particles with a critical supersaturation $\left(\mathrm{SS}_{\mathrm{c}}\right)$ less than the instrument SS will grow to droplet size. The detection stage lasts for $20 \mathrm{~s}$ during which a steady SS is maintained within the chamber (Snider et al., 2006). The entire process takes 30 to $40 \mathrm{~s}$ including the time needed to flush the old sample out of the chamber, admit the new sample, and achieve the steady state SS which can be as much as $15 \mathrm{~s}$ depending on how long it takes for the temperature gradient within the chamber to stabilize (Delene and Deshler, 2000; Snider et al., 2006).

A laser illuminates the center of the chamber (assumed to be the region of maximum SS) where the light is scattered by cloud droplets forming on activated CCN. The amount of scattering is monitored by a photodetector and can be used to derive the number concentration of large particles (droplets) in the chamber. During the detection stage the scattering increases as droplets grow. If the SS of the chamber exceeds the $\mathrm{SS}_{\mathrm{c}}$ of some of the particles, these will activate and begin to fall. The photodetector voltage reaches its peak value at this point. The peak voltage is used to determine the $N_{\text {ccn }}$. The relationship between the light scattering, as indicated by the peak photodetector voltage, and the droplet number concentration is calibrated by testing an aerosol population with a $100 \%$ activated fraction and known number concentration (Snider et al., 2006). The variability in the resulting peak voltage measured for test aerosol populations with the same $N_{\text {ccn }}$ is used to estimate the uncertainty associated with the CCN instrument detector as shown by Snider et al. (2006).

The temperature gradient within the chamber is monitored by thermocouples and the nominal SS $\left(\mathrm{SS}_{\mathrm{nom}}\right)$ is computed from the reported temperature gradient and chambertop temperature. Water vapor is supplied to the chamber by wetted pads that are re-moistened every $1-2 \mathrm{~h}$. Snider et al. (2006) report that the activation behavior of particles in the CCNC-100A is characteristic of a SS below the $\mathrm{SS}_{\text {nom }}$. They define an effective SS ( $\left.\mathrm{SS}_{\text {eff }}\right)$ to describe this behavior, and explain the method for computing $\mathrm{SS}_{\text {eff }}$ and the associated uncertainty. Three $\mathrm{SS}_{\text {nom }}$ settings were used during ISPA-III and correspond to average values for $\mathrm{SS}_{\text {eff }}$ of $0.22 \%, 0.46 \%$ and $0.96 \%$. The $\mathrm{SS}_{\text {eff: }}: \mathrm{SS}_{\text {nom }}$ ratio and associated uncertainty are estimated during a chamber calibration in which the activation behavior of size-selected ammonium sulfate particles is tested (Snider et al., 2010). The true chamber SS can be determined from the activation behavior of the ammonium sulfate and a Köhler theory model (Snider et al., 2006). This is compared to the theoretical $\mathrm{SS}_{\text {nom }}$ to give $\mathrm{SS}_{\text {eff }}: \mathrm{SS}_{\text {nom. }}$. For ISPA-III, the original chamber calibration found $\mathrm{SS}_{\text {eff }}: \mathrm{SS}_{\mathrm{nom}}=0.61$. During the project a plate temperature sensor failed and the result of a new calibration $\left(\mathrm{SS}_{\mathrm{eff}}: \mathrm{SS}_{\mathrm{nom}}=0.7\right)$ was retroactively applied to data collected after the failure (11 December through 19 December). Using results from Snider et al. (2006) the chamber calibration uncertainty is estimated to be $10 \%$ of $\mathrm{SS}_{\mathrm{eff}}: \mathrm{SS}_{\mathrm{nom}}$ for the current study. It is assumed in the following analysis that the $\mathrm{SS}_{\text {eff }}$ represents the true SS experienced by particles within the chamber and will be referred to simply as SS for the remaining discussion of this instrument and its measurements.

The PCASP is an optical particle counter, measuring the forward scattered light from particles passing through a laser beam (Snider and Petters, 2008). The scattering is relative to particle size (assuming particles are spherical and have an index of refraction equal to 1.59) so particles can be separated into size bins. The PCASP defines 30 bins of particle concentrations but the lower size limit of the first bin is uncertain. Data from the 29 bins with certain bin limits comprise a range of particle diameters between 0.122 to $3 \mu \mathrm{m}$. It is assumed that particles are classified into size bins by their dry diameter. However, hygroscopic particles deliquesce at relative humidity (RH) well below $100 \%$. To ensure that the PCASP sampling environment is dry enough to rule out wetted particles, heaters are installed at the inlet. The sample flow rate is not constant but averages about $1 \mathrm{~cm}^{3} \mathrm{~s}^{-1}$. The bin number concentration is defined as the count rate divided by the flow rate for each sample.

\subsection{ISPA flight plan}

Clear-sky aerosols were targeted for measurement during the King Air flights with the additional goal of sampling in different large-scale flow regimes. Eight days during the project period (1 December to 19 December) were considered clear enough to collect a complete cloud free dataset along the Western Slope. Flight days were separated into three flow regimes based on the general direction of the wind at $700 \mathrm{mb}$ and $500 \mathrm{mb}$ in the western United States. Composite images of $500 \mathrm{mb}$ heights for each regime are shown in Fig. 6. The westerly regime was characterized by zonal flow from the west coast through Colorado. The remaining flights were conducted on days with a $500 \mathrm{mb}$ ridge to the west of Colorado and a trough to the east. The amplitude of the ridge/trough pattern dictated whether flow through western Colorado was northwesterly or northerly. Distant sources of particles to the southwest, such as the southern California urban areas, were of interest but unfortunately no episodes of southwest flow were observed.

Dates and other information about each flight are given in Table 2. As indicated in Table 2, two separate flight plans were used (shown in Fig. 1). The first was used for the westerly and northwesterly regimes. Vertical profiles were taken just west of Steamboat Springs and over Cortez. These were done in "vertical stacks" where the aircraft flies at a constant altitude for $40-60 \mathrm{~km}$ then turns 180 degrees and abruptly rises, repeating the $40-60 \mathrm{~km}$ leg at a higher altitude and in the opposite direction. The stacks included 5 altitudes, the 
Table 2. Flight dates and information about the flight paths, flow regimes, and data observed for all King Air flights in December 2009. Note that the flight duration is the total time from the southward and northward flights from each day.

\begin{tabular}{lllccll}
\hline Flight & Date & $\begin{array}{l}\text { Launch } \\
\text { time (UTC) }\end{array}$ & $\begin{array}{c}\text { Duration } \\
\text { (hours) }\end{array}$ & $\begin{array}{l}\text { Flight } \\
\text { Plan \# }\end{array}$ & $\begin{array}{l}\text { Stacks } \\
\text { (AM,PM) }\end{array}$ & Flow \\
\hline F1 & $12 / 3 / 09$ & $17: 05$ & 4.7 & 2 & Steamboat Springs (SB), Nucla (Nc) & N \\
F2 & $12 / 5 / 09$ & $16: 06$ & 5.6 & 1 & SB & W \\
F3 & $12 / 10 / 09$ & $16: 25$ & 5.3 & 1 & & NW \\
F4 & $12 / 11 / 09$ & $17: 27$ & 6.0 & 1 & SB, Cortez (Cz) & W \\
F5 & $12 / 15 / 09$ & $16: 01$ & 6.0 & 1 & $\mathrm{SB}, \mathrm{Cz}$ & $\mathrm{W}$ \\
F6 & $12 / 17 / 09$ & $16: 07$ & 6.0 & 1 & $\mathrm{SB}, \mathrm{SB}$ & $\mathrm{NW}$ \\
F7 & $12 / 18 / 09$ & $16: 47$ & 6.3 & 1 & $\mathrm{Cz}, \mathrm{SB}$ & $\mathrm{NW}$ \\
F8 & $12 / 19 / 09$ & $15: 59$ & 5.8 & 2 & $\mathrm{SB}, \mathrm{Nc}$ & $\mathrm{N}$ \\
\hline
\end{tabular}
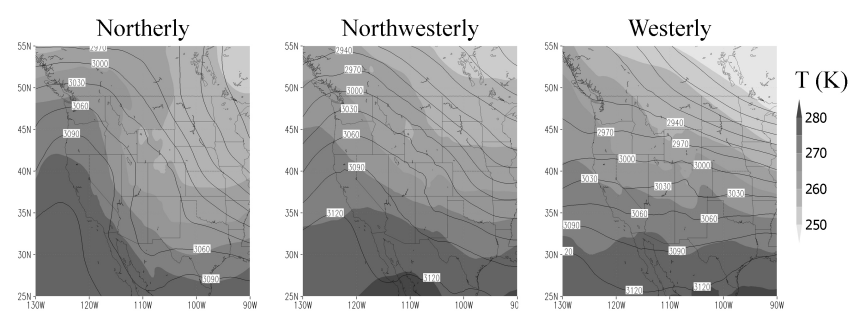

Fig. 6. Composite of $700 \mathrm{mb}$ geopotential height and temperature for the northerly, northwesterly, and westerly flow regime cases. Temperature (shaded) is in units of $\mathrm{K}$ and height (contours) is in geopotential meters.

lowest between $250-500 \mathrm{~m}$ a.g.l. and increasing about $500 \mathrm{~m}$ on each leg with some variation. Flight plan \#2 was used during northerly wind events. It differed in the location of the southern stack, which was moved north to Nucla to sample flow into the San Juan Mountains better in this regime. Each flight day contained two flights with a stop at a southern Colorado airport for refueling. These airports were Cortez (CTZ; see Fig. 1) for flight plan \#1 and Montrose for flight plan \#2 (MJT; see Fig. 1). The north to south transects were similar in both flight plans. These were flown at constant height above mean sea level meaning the distance above ground level varied, but in general this was less than $1000 \mathrm{~m}$ a.g.l. The flight leg between Laramie and the northern stack was necessarily run at higher altitudes and was used for instrument setup. Data from this leg are not included in the analysis.

\subsection{Results}

The $N_{\text {ccn }}$ data collected on these flight paths underwent a check for quality of the photodetector voltage output. The percentages of valid measurements for the entire project at each SS setting were $55 \%$ (SS $\approx 0.22 \%$ ), $76 \%$ ( $\mathrm{SS} \approx 0.46 \%$ ), and $85 \%$ (SS $\approx 0.96 \%)$. Flagged measurements of $N_{\text {ccn }}$ were set to missing. PCASP aerosol size distribution bins and CPC particle number were averaged over $20 \mathrm{~s}$ time periods ( 20 observations), beginning ten seconds before the $\mathrm{CCN}$ instrument chamber opened and ending ten seconds after it was opened. The averaged values were then matched with the derived $N_{\mathrm{ccn}}$.

Figure 7a shows the average $N_{\mathrm{ccn}}$ for all valid data points, except those collected during the vertical profiles, plotted against SS. The mean observed $N_{\text {ccn }}$ indicate a somewhat clean atmosphere with the majority of the observations of $N_{\text {ccn }}<100 \mathrm{~cm}^{-3}$ at the lowest SS. This plot also illustrates the expected increase in $N_{\mathrm{ccn}}$ with increasing SS that has been represented using the power law relationship from Twomey (1959). The dataset is separated into large-scale flow regimes, as defined in Fig. 6, and the composite plots are shown as different colors (Fig. 7b-d). The mean $N_{\text {ccn }}$ was similar for the northerly (Fig. 7b) and northwesterly regimes (Fig. 7c), although the latter showed less variation at each SS. The westerly regime (Fig. 7d) was cleaner in general, with a mean $N_{\text {ccn }}$ of about $50 \mathrm{~cm}^{-3}$ at SS $\approx 0.22 \%$. The particle number concentration measured by the PCASP (for bins with known size limits, that is particles over $D=0.122 \mu \mathrm{m}$ ) is shown in Fig. 7 to fall between the $N_{\mathrm{ccn}}$ at the middle and highest SS settings in the CCN instrument. This could indicate the presence of a population of particles that are smaller than $D=0.122 \mu \mathrm{m}$ but will activate at high SS despite their small size.

To test for spatial trends in the $N_{\mathrm{ccn}}$ at $\mathrm{SS} \approx 0.22 \%$ along the horizontal transects, the data were binned by latitude. The latitude bins were averaged and plotted for all transects in Fig. 8. $N_{\mathrm{ccn}}$ averaged higher in the northern portion of the flights, but the difference was small. In general, $N_{\text {ccn }}$ varied little along the Western Slope. The latitude bin-average $N_{\mathrm{cn}}$ is also plotted on Fig. 8 (on a different scale) to show the variation in activated fraction. Values of activated fraction were low in magnitude across the entire flight track, although higher in the southern portions than in the north. On average, only $5-10 \%$ of particles counted by the CPC were counted as $\mathrm{CCN}$ by the $\mathrm{CCN}$ instrument. The implications are that greater than $90 \%$ of the ambient particles along the flight track were too small or non-hygroscopic to activate droplets at this SS. 


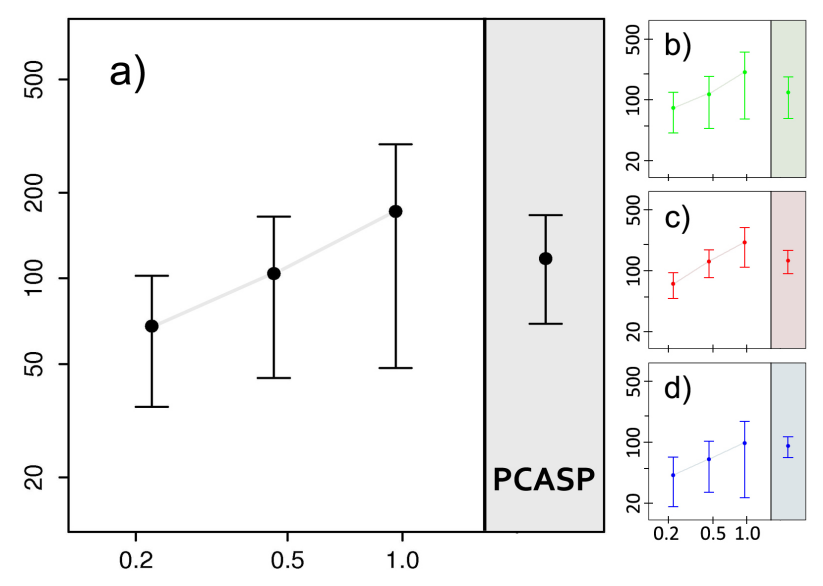

Fig. 7. Plots of $N_{\mathrm{ccn}}\left(\mathrm{y}\right.$-axis; $\log$ scale; $\mathrm{cm}^{-3}$ ) at the CCN instrument SS (x-axis; log scale; \%) for (a) all King Air horizontal transects, (b) transects through northerly flow, (c) northwesterly flow, and (d) westerly flow. The mean $N_{\text {ccn }}$ are marked with filled circles and the error bars represent one standard deviation from the mean. The mean and standard deviation of the PCASP total number concentration is shown in the shaded region of each plot.

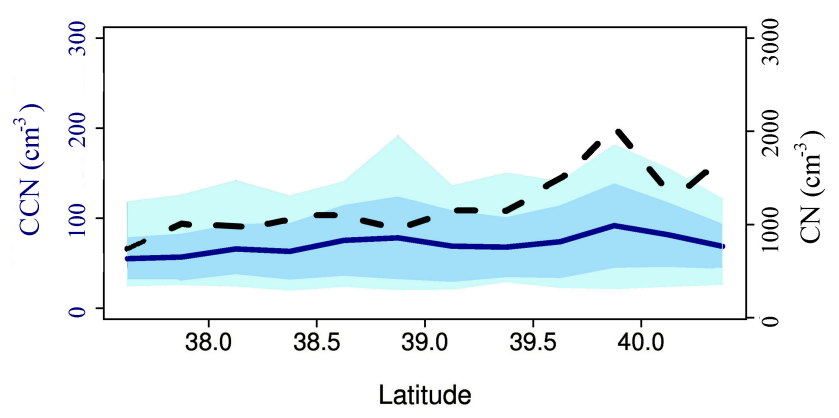

Fig. 8. $N_{\mathrm{ccn}}(\mathrm{SS} \approx 0.22 \%)$ and $N_{\mathrm{cn}}$ plotted against latitude for all horizontal transects. The data were binned by latitude and averaged. The $N_{\mathrm{ccn}}$ is plotted as the blue, solid line. The dark blue shaded region represents one standard deviation from the mean for each latitude bin and the range in values in each bin is represented with the light blue shaded region. Bin averaged $N_{\mathrm{cn}}$ is plotted as the black, dashed line and uses the scale on the right-hand side.

Data collected during the vertical stacks also exhibit a low activated fraction. A distance of $40-60 \mathrm{~km}$ was flown at each stack leg to collect several data points at each SS at a constant altitude, and legs were repeated if necessary. The data were averaged over each altitude, disregarding horizontal variations in sampling along the flight leg. For the purpose of plotting these data, any stack leg with less than 3 valid data points was set as missing. The altitude of the stacks sometimes varied between profiles, often because clouds were encountered at target altitudes. The approximate ground levels at the three locations are 2100 m.s.l. for Steamboat Springs, 1840 m.s.l. for Cortez and 1850 m.s.l. for Nucla.

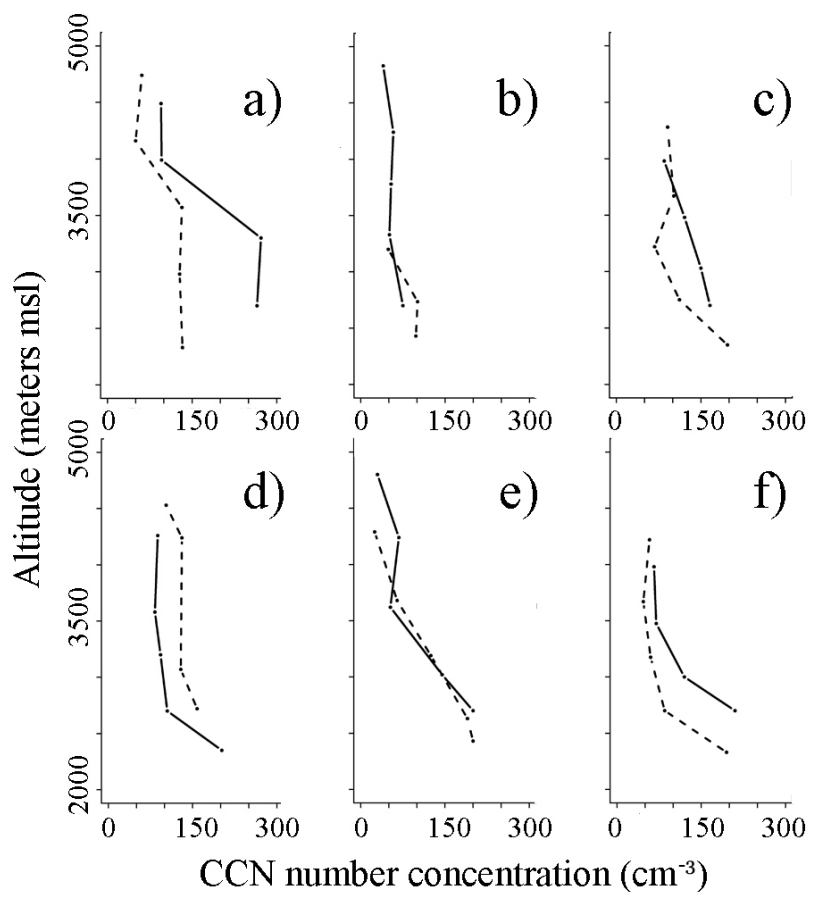

Fig. 9. Vertical profiles of $N_{\mathrm{ccn}}$ collected during the (a) F1, (b) F4, (c) F5, (d) F6, (e) F7, (f) F8 flights. The plotted values are $N_{\mathrm{ccn}}$ at $\mathrm{SS}=0.46 \%$ for the northern stacks (solid line) and the southern stacksSupersaturation (SS) is maintained (dashed line).

The vertical profiles are given in Fig. 9 for all stacks. They are set in order by date and time flown and show $N_{\mathrm{ccn}}$ at $\mathrm{SS} \approx 0.46 \%$ for both the northern and southern stack locations. In general, the King Air flew through higher number concentrations of particles and CCN in the lowest level of the stack compared to the highest level. This difference was most pronounced on the F7 and F8 flights for both northern and southern stacks (Fig. 9e and f). Still, the average $N_{\text {ccn }}$ measured at $\mathrm{SS} \approx 0.46 \%$ never exceeded $300 \mathrm{~cm}^{-3}$ even at the lowest altitudes. Activated fraction did not vary considerably with height for the majority of profiles.

On the F1 and F5 flights (Fig. 9a and c), $N_{\mathrm{ccn}}$ and $N_{\mathrm{cn}}$ did not decrease constantly with altitude. Instead, a relative clean layer was observed on these days with slightly higher $N_{\text {ccn }}$ and $N_{\text {cn }}$ in the altitudes above the clean layer. During the F1 stacks the clean layer was evident in both the northern and southern profiles and at similar altitudes. For F5, the clean layer was more pronounced in the southern stack and difficult to discern in the northern stack.

Very similar trends in $N_{\mathrm{ccn}}$ and $N_{\mathrm{cn}}$ with height were observed between the northern and southern stacks for F1, F6, F7 and F8 (Fig. 9a, d, e, f). In general, the magnitudes of $N_{\text {ccn }}$ and $N_{\text {cn }}$ were also similar on these days (with the exception of F1), all of which were characterized by northerly or northwesterly flow. This suggests that the King Air was sampling within the same, or similar airmasses. Aerosol measurements are more available in northwestern Colorado 
in comparison to southwestern Colorado. It now appears that, especially under north and northwesterly winds, the northern measurements could be used to estimate $N_{\mathrm{ccn}}$ in the southern locations. In contrast, the vertical profiles for the westerly flow flights F4 and F5 do not appear to be as consistent from north to south. Differences in aerosol sources to the west of the Colorado mountains may lead to these inconsistencies with westerly winds.

\subsection{CCN prediction}

\subsubsection{CCN closure review}

$\mathrm{CCN}$ closure is regarded as one of the most effective techniques for evaluating the characteristics of aerosols that affect their potential to act as $\mathrm{CCN}$ and assessing our ability to predict this activity. A CCN closure study, as explained by VanReken et al. (2003), is an attempt to match observed CCN number concentrations with those predicted using one of several methods, usually involving knowledge of the aerosol size distribution, composition, or both. Squires and Twomey (1961) and Twomey and Warner (1967) published two of the earliest studies along these lines, although their goal was to show a predictive relationship between $\mathrm{CCN}$ and CDNC observed in the low-levels of nearby clouds.

More recent closure studies use Köhler theory to model $N_{\text {ccn }}$ at a fixed SS. Covert et al. (1998) describe one of the first attempts at $\mathrm{CCN}$ closure using this method. They measured $N_{\text {ccn }}$ with a static diffusion, thermal gradient instrument at a coastal site in southern Australia. Simultaneous observations of aerosol size distribution and hygroscopic growth were made. For each sample the critical dry size for droplet activation was computed from the Köhler equations using the hygroscopic growth information and temperature and SS set in the CCN instrument. The number of observed particles larger than the critical size is counted and regarded as the prediction of $N_{\mathrm{ccn}}$ used to test for closure. Covert et al. (1998) found that $N_{\mathrm{ccn}}$ was, on average, overpredicted by about $20 \%$. Subsequent studies have achieved a wide range of results with respect to CCN closure. Chuang et al. (2000) systematically, and substantially, underpredicted $\mathrm{CCN}$ in marine aerosol samples. The majority of their error probably resulted from instrument bias but they also note the importance of the treatment of aerosol composition in CCN prediction. This was also pointed out in earlier work by Liu et al. (1996) who combined aerosol composition measurements with $\mathrm{CCN}$ predictions and found that some chemical constituents were correlated with $N_{\text {ccn }}$.

A CCN closure study in south Florida reported by VanReken et al. (2003) found excellent agreement between measured and predicted $N_{\text {ccn }}$ assuming all particles were composed of pure ammonium sulfate. While they speculated that the simplified representation of aerosol composition might apply in other environments, this was not the case for rural continental aerosol sampled by Medina et al. (2007). They observed CCN and size-dependent aerosol composition at a site in southern New Hampshire for 7 days in August. By including a size-dependent insoluble fraction parameter, based on the observations, in their CCN model, they realized substantial improvement in $\mathrm{CCN}$ predictions relative to $\mathrm{CCN}$ measurements. Chang et al. (2007) reached similar conclusions in a 14-day dataset of size-dependent aerosol composition in CCN measurements in a semi-rural environment.

Recent attempts have focused on measuring aerosol composition as the key to achieving CCN closure (Ervens et al., 2007; Quinn et al., 2008; Furutani et al., 2008; Bougiatioti et al., 2009). Broekhuizen et al. (2006) and Cubison et al. (2008) both show evidence that CCN closure can be improved with knowledge of size-dependent composition. $\mathrm{Cu}$ bison et al. (2008) also found that assumptions about the aerosol mixing state (internal or external) can adversely impact CCN predictions. They sampled aerosol near Los Angeles, California in an urban airmass. For this case, assuming an external mixture of aerosol increased the accuracy of the CCN predictions. The assumption of externally mixed aerosol was also used by Stroud et al. (2007) to improve $\mathrm{CCN}$ closure at a polluted site in North Carolina. The work of Stroud et al. (2007) aptly reflects the current state of CCN closure studies by pointing out that inadequate understanding of aerosol composition effects on hygroscopicity and instrument inaccuracies are the main barriers to achieving $\mathrm{CCN}$ closure.

\subsubsection{CCN closure attempt}

As in the studies outlined above, to predict $N_{\mathrm{ccn}}$ for the King Air horizontal transects, information about the aerosol size distribution and composition are applied to a model of Köhler theory. Petters and Kreidenweis (2007) show how the representation of the hygroscopic growth of a particle solution in Köhler theory can be simplified using a single, empirically-derived parameter, $\kappa$. This is given in Eq. (6) from Petters and Kreidenweis (2007):

$$
S(D)=\frac{D^{3}-D_{d}^{3}}{D^{3}-D_{d}^{3}(1-\kappa)} \exp \left[\frac{4 \sigma_{s / a} M_{\mathrm{w}}}{R T \rho_{\mathrm{w}} D}\right]
$$

Here the saturation ratio, $S$, is shown as a function of the solution diameter, where $D$ is the diameter of the droplet solution, $D_{d}$ is the dry particle diameter, $\sigma_{s / a}$ the surface tension of the solution/air interface, $M_{\mathrm{w}}$ the molecular weight of water, $R$ is the universal gas constant, $T$ is the temperature and $\rho_{\mathrm{W}}$ is the density of water. The $\kappa$ parameter is determined experimentally for different aerosol species and is listed by Petters and Kreidenweis (2007) for most common aerosol constituents. Since its introduction, $\kappa$ has been used to represent hygroscopicity (relative ability of a particle to grow by vapor condensation) in both observational (e.g. Shantz et al., 2008; Gunthe et al., 2009; Koehler et al., 2009) and modeling studies (e.g. Reutter et al., 2009; Eidhammer et al., 2009). Here the Petters and Kreidenweis (2007) $\kappa$-Köhler 
theory is used to predict $N_{\mathrm{ccn}}$ from the King Air measurements. A constant value of $T=298.15 K$ is used for these calculations. This is considerably warmer than the average $\mathrm{CCN}$ instrument chamber temperature but is consistent with the standard values for $\sigma_{s / a}$ given in Petters and Kreidenweis (2007). Snider et al. (2010) show that the particle $\mathrm{SS}_{\mathrm{c}}$ can be sensitive to the temperature-dependence of $\sigma_{s / a}$ and recommend using the standard values (as done here) where the temperature-dependence is not accounted for.

Size distribution data for $N_{\text {ccn }}$ prediction are given by the PCASP but since composition measurements were not taken in flight, a reasonable estimate for the average $\kappa$ must be used instead. This estimate is, unfortunately, constrained by the detection limits of the PCASP. The PCASP lower limit for measurements between known bin size bounds was given as $0.122 \mu \mathrm{m}$ earlier in this section. However, even at $\mathrm{SS}=0.22 \%$ a particle with the $\kappa$ of ammonium sulfate will have a critical dry diameter of $0.077 \mu \mathrm{m}$ using the $T$ and other constants given in Petters and Kreidenweis (2007). Therefore, if the value of $\kappa$ for ammonium sulfate was used to predict $N_{\mathrm{ccn}}$, an unmeasured portion of the aerosol size distribution would exist above the critical size. These particles would go uncounted and $N_{\text {ccn }}$ could be underpredicted considerably. Only less hygroscopic particles would possess a critical dry diameter larger than $0.122 \mu \mathrm{m}$. To ensure that the computed critical size will fall within the detection range of the PCASP at SS $=0.22 \%$ a value of $\kappa \leq 0.15$ must be assumed. A value of $\kappa=0.1$ is used for this study. This is equivalent to assuming the sampled aerosols have a low hygroscopicity, more characteristic of organic aerosol species than inorganics, such as sulfates or nitrates. The assumption of low hygroscopicity is, therefore, inconsistent with observations from the IMPROVE network site at Mount Zirkel (MOZI) in the Colorado Park Range which show a large inorganic component. The composition of the $\mathrm{PM}_{2.5}$ aerosol sampled at MOZI in December from 1999-2008 averaged more than $50 \%$ sulfate and nitrate by mass. This is corroborated by the analysis of Borys et al. (2000) who found substantial sulfate and nitrate mass in cloud water samples collected at SPL during the winter. Richardson et al. (2007) used an aerosol mass spectrometer and other methods to measure aerosol composition at SPL during April and May of 2004. They also found high proportions of inorganic compounds that dominated the total aerosol mass except during dust events. In light of these observations, it should be noted that the hygroscopicity value used in this analysis is likely a low estimate.

Using the estimated $\kappa=0.1$, a critical diameter is computed using the form of the Köhler equations given as Eq. (2). This is done separately for each data point since the SS varies between measurements. Particles in size bins greater than the critical size, as counted by the PCASP, are summed. The sum is regarded as the predicted $N_{\text {ccn }}$. Note, due to the limitations of the PCASP size range, only CCN measurements at $\mathrm{SS} \approx 0.22 \%$ were used in this analysis. A more robust method for predicting $N_{\mathrm{ccn}}$ from aerosol size distribution in-

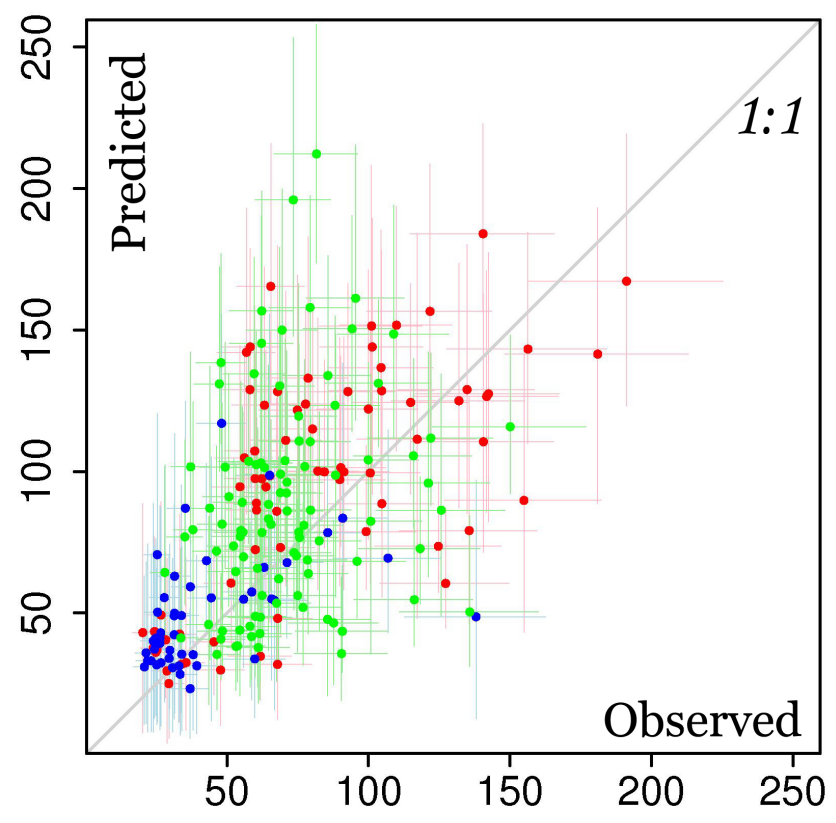

Fig. 10. Observed vs. predicted $N_{\mathrm{ccn}}\left(\mathrm{cm}^{-3}\right)$ for all horizontal transects during westerly flow (blue), northwesterly flow (green), and northerly flow (red). Error bars are defined in the text. The 1:1 relation line is plotted.

formation was introduced by Petters et al. (2007) but this method requires size-selection of particles during sampling.

Figure 10 shows the predicted $N_{\text {ccn }}$ plotted against the measured $N_{\text {ccn }}$ for all horizontal transects. Error bars depict the estimated uncertainty for the CCNC-100A measurements and the PCASP counts (which were used to derive the predicted $\left.N_{\mathrm{ccn}}\right)$. For the CCNC-100A, the uncertainty is estimated from the detector calibration using the fitting method shown in Snider et al. (2006). The predicted $N_{\text {ccn }}$ uncertainty is plotted as plus and minus the standard deviation of the 20 PCASP measurements (taken $10 \mathrm{~s}$ before and after the $\mathrm{CCN}$ instrument chamber was opened) of the number concentration of particles with diameters larger than the computed critical diameter. The error bars extend from values of $N_{\text {ccn }}$ predicted for SS $=\mathrm{SS} \pm 0.1 \times \mathrm{SS}$ to account for the uncertainty in the chamber SS (Sect. 3.1.1).

Despite the low prescribed value of $\kappa$ compared to nearby observations of aerosol composition, the data do not exhibit an underprediction bias. There are several possible explanations for this unexpected result. First, the ambient aerosol during this project could have been dominated by organic compounds which are characterized by low hygroscopicity. This conclusion is at odds with the IMPROVE dataset and other published observations in the region. If the ISPA-III ambient aerosol hygroscopicity was more consistent with these previous composition observations (i.e. the ambient aerosol $\kappa$ was higher than $\kappa$ assumed for the closure study), it is possible that the predicted $N_{\mathrm{ccn}}$ were simply insensitive 
to variations in aerosol composition. However, parcel model results suggest that at the low SS used here some sensitivity could be expected (Ward et al., 2010). A final explanation is suggested by Shantz et al. (2008). They note that the light scattering within the $\mathrm{CCN}$ instrument is proportional to droplet number, but also droplet size. The pure ammonium sulfate particles used in the detector calibration are likely to be more hygroscopic than internally mixed ambient aerosols and, therefore, will grow at a higher rate and possibly scatter more light within the instrument chamber. This could result in a low number bias when the $\mathrm{CCN}$ instrument samples ambient, presumably less hygroscopic particles. Additional detector calibrations using particles with a different hygroscopicity than ammonium sulfate would be needed to explore this possible explanation. Figure 10 also shows substantial spread of the data points but in general, $N_{\mathrm{ccn}}$ was predicted within a factor of three when compared to the measurements.

The CCN closure plot is separated into flow regime by colors in Fig. 10. The noted differences in magnitude of $N_{\text {ccn }}$ between regimes are apparent. Low values of $N_{\mathrm{ccn}}$, mainly between 30 and $50 \mathrm{~cm}^{-3}$, were observed under westerly flow and these were consistently underpredicted. Observations under northwesterly flow show the largest average deviation from the plotted 1:1 relation line. This could indicate a change in aerosol mixing state or average composition sampled during these flights.

\section{Summary and conclusions}

In combination with observations from MVNP and SPL, the foundation for fall and winter season $\mathrm{CCN}$ climatologies now exists for the Western Slope. The $N_{\mathrm{ccn}}$ and activated fractions are consistent with remote continental, aged aerosol. These characteristics were true from SPL, south to MVNP, and somewhat consistent in time as well as space. This result suggests that variability of $\mathrm{CCN}$ in this region may be less important than originally thought. This has implications for studies of aerosol effects on orographic clouds in this region. CCN transported to the San Juan Mountains and other locations along the Western Slope can be estimated by the available measurements from northwestern Colorado, at least for particular wind regimes and seasons. This may also be encouraging from a modeling perspective. The lack of variability associated with CCN along the Western Slope could justify simplified representations of aerosols in numerical simulations, provided the simplifications are based on averaged observed quantities.

Several conclusions about the nature of CCN flowing into the Colorado Rocky Mountains from the Western Slope can be drawn from these results. The CCN observed at SPL, MVNP, and on a line between the two sites, was characteristic of rural continental aerosol as defined by Seinfeld and Pandis (2006). For rural continental aerosols, the particle number distribution is dominated by a nuclei (Aitken) mode, particle surface area is largest in the accumulation mode, and particle mass is dictated by a small number of coarse mode particles.

According to Seinfeld and Pandis (2006), the nuclei mode receives its largest contributions of particles from local anthropogenic sources. This is difficult to reconcile with the December observations of CCN along the Western Slope that suggest local sources make only minor contributions to the regional $\mathrm{CCN}$ field. One explanation is that number fluctuations in the nuclei mode do not impact $\mathrm{CCN}$ at the instrument SS due to their small size. The CCN in this region would then be dependent on the aged, accumulation mode particles that are more likely to have distant origins. The observations from MVNP, where $N_{\mathrm{cn}}$ was highly variable but $N_{\mathrm{ccn}}$ changed slowly and within a much smaller range, support this view. Additionally, the low activated fraction computed from the measurements suggests that a large number of the ambient particles are too small to activate droplets at the set values of SS.

Many questions remain unanswered, especially concerning the sources of the $\mathrm{CCN}$, and potential differences with season that are not captured here. Future studies should incorporate aerosol composition measurements, as suggested by Medina et al. (2007) or include size-separated CCN sampling as an estimate of aerosol hygroscopicity as in Petters et al. (2007). With these additional measurements the conclusions of this work could be better substantiated.

Acknowledgements. The authors would like to thank George San Miguel of the National Park Service and Ian McCubbin of the Desert Research Institute (DRI), as well as Larry Oolman and the rest of the King Air facility staff for essential logistical support. We would also like to acknowledge Doug Lowenthal of DRI for assistance with the Mesa Verde dataset. We are grateful for the comments and suggestions from Jeff Snider and an anonymous reviewer that improved this manuscript. This work was funded by the National Science Foundation grant ATM-0835421.

Edited by: M. Gysel

\section{References}

Andreae, M. O.: Aerosols before pollution, Science, 315, doi:10.1126/science.1136529, 2007.

Andreae, M. O. and Rosenfeld, D.: Aerosol-cloudprecipitation interactions, Part 1, The nature and sources of cloud-active aerosols, Earth-Sci. Rev., 89, doi:10.1016/j.earscirev.2008.03.001, 2008.

Borys, R. D., Lowenthal, D. H., and Mitchell, D. L.: The relationship among cloud microphysics, chemistry, and precipitation rate in cold mountain clouds, Atmos. Environ., 34, 2593-2602, 2000.

Borys, R. D., Lowenthal, D. H., Cohn, S. A., and Brown, W. O. J.: Mountaintop and radar measurements of anthropogenic aerosol effects on snow growth and snowfall rate, Geophys. Res. Lett., 30(10), doi:10.1029/2002GL016855, 2003. 
Bougiatioti, A., Fountoukis, C., Kalivitis, N., Pandis, S. N., Nenes, A., and Mihalopoulos, N.: Cloud condensation nuclei measurements in the marine boundary layer of the Eastern Mediterranean: CCN closure and droplet growth kinetics, Atmos. Chem. Phys., 9, 7053-7066, doi:10.5194/acp-9-7053-2009, 2009.

Broekhuizen, K., Chang, R.Y.-W., Leaitch, W. R., Li, S.-M., and Abbatt, J. P. D.: Closure between measured and modeled cloud condensation nuclei $(\mathrm{CCN})$ using size-resolved aerosol compositions in downtown Toronto, Atmos. Chem. Phys., 6, 2513-2524, doi:10.5194/acp-6-2513-2006, 2006.

Chang, R. Y.-W., Liu, P. S. K., Leaith, W. R., and Abbatt, J. P. D.: Comparison between measured and predicted CCN concentrations at Egbert, Ontario: Focus on the organic aerosol fraction at a semi-rural site, Atmos. Environ., 41, 8172-8182, 2007.

Charlson, R. J., Seinfeld, J. H., Nenes, A., Kulmala, M., Laaksonen, A., and Facchini, M. C.: Reshaping the theory of cloud formation, Science, 292, 2025-2026, 2001.

Chuang, P. Y., Collins, D. R., Pawlowska, H., Snider, J. R., Jonsson, H. H., Brenguier, J. L., Flagan, R. C., and Seinfeld, J. H.: CCN measurements during ACE-2 and their relationship to cloud microphysical properties, Tellus, 52B, 843-867, 2000.

Covert, D. S., Gras, J. L., Wiedensohler, A., and Stratmann, F.: Comparison of directly measured $\mathrm{CCN}$ with $\mathrm{CCN}$ modeled from the number-size distribution in the marine boundary layer during ACE 1 at Cape Grim, Tasmania, J. Geophys. Res.-Atmos., 103, 16597-16608, 1998.

Cubison, M. J., Ervens, B., Feingold, G., Docherty, K. S., Ulbrich, I. M., Shields, L., Prather, K., Hering, S., and Jimenez, J. L.: The influence of chemical composition and mixing state of Los Angeles urban aerosol on CCN number and cloud properties, Atmos. Chem. Phys., 8, 5649-5667, doi:10.5194/acp-8-5649-2008, 2008.

DeBell, L. J., Gebhart, K. A., Hand, J. L., Malm, W. C., Pitchford, M. L., Schichtel, B. A., and White, W. H.: Spatial and seasonal patterns and temporal variability of haze and its constituents in the United States: Report IV, Colorado State University, Fort Collins, CO, 2006.

Delene, D. J. and Deshler, T.: Calibration of a photometric cloud condensation nucleus counter designed for deployment on a balloon package, J. Atmos. Oceanic Technol., 17, 459-467, 2000.

Delene, D. J. and Deshler, T.: Vertical profiles of cloud condensation nuclei above Wyoming, J. Geophys. Res.-Atmos., 106(D12), 12579-12588, 2001.

Eidhammer, T., DeMott, P. J., and Kreidenweis, S. M.: A comparison of heterogeneous ice nucleation parameterizations using a parcel model framework, J. Geophys. Res.-Atmos., 114, D06202, 19 pp., doi:10.1029/2008JD011095, 2009.

Eltgroth, M. W. and Hobbs, P. V.: Evolution of particles in the plumes of coal-fired power-plants 2. Numerical-model and comparisons with field measurements, Atmos. Environ., 13, 953975, 1979.

Ervens, B., Cubison, M., Andrews, E., Feingold, G., Ogren, J. A., Jimenez, J. L., DeCarlo, P., and Nenes, A.: Prediction of cloud condensation nucleus number concentration using measurements of aerosol size distributions and composition and light scattering enhancement due to humidity, J. Geophys. Res.-Atmos., 112, D10S32, 15 pp., doi:10.1029/2006JD007426, 2007.

Furutani, H., Dall'osto, M., Roberts, G. C., and Prather, K. A.: Assessment of the relative importance of atmospheric aging on
CCN activity derived from field observations, Atmos. Environ., 42, 3130-3142, 2008.

Ghan, S. J. and Schwartz, S. E.: Aerosol properties and processes, B. Am. Meteorol. Soc., 88, 1059-1083, 2007.

Givati, A. and Rosenfeld, D.: Quantifying precipitation suppression due to air pollution, J. Appl. Meteorol., 44, 1298-1315, 2004.

Gunthe, S. S., King, S. M., Rose, D., Chen, Q., Roldin, P., Farmer, D. K., Jimenez, J. L., Artaxo, P., Andreae, M. O., Martin, S. T., and Pöschl, U.: Cloud condensation nuclei in pristine tropical rainforest air of Amazonia: size-resolved measurements and modeling of atmospheric aerosol composition and CCN activity, Atmos. Chem. Phys., 9, 7551-7575, doi:10.5194/acp-9-75512009, 2009.

Hobbs, P. V., Stitch, J. L., and Radke, L. F.: Cloud-active nuclei from coal-fired electric power plants and their interactions with clouds, J. Appl. Meteorol., 19, 439-451, 1980.

Hudson, J. G.: Variability of the relationship between particle size and cloud-nucleating ability, Geophys. Res. Lett., 34, L08801, 5 pp., doi:10.1029/2006GL028850, 2007.

Hyslop, N. P. and White, W. H.: An evaluation of interagency monitoring of protected visual environments (IMPROVE) collocated precision and uncertainty estimates, Atmos. Environ., 42, 26912705, 2008.

Jirak, I. L. and Cotton,W. R.: Effect of air pollution on precipitation along the front range of the Rocky Mountains, J. Appl. Meteorol. Clim., 45, 236-246, 2006.

Kaufman, Y. J., Tanre, D., and Boucher, O.: A satellite view of aerosols in the climate system, Review, Nature, 419, 215-223, 2002.

Koehler, K. A., Kreidenweis, S. M., DeMott, P. J., Petters, M. D., Prenni, A. J., and Carrico, C. M.: Hygroscopicity and cloud droplet activation of mineral dust aerosol, Geophys. Res. Lett., 36, L08805, 5 pp., doi:10.1029/2009GL037348, 2009.

Levin, Z. and Cotton, W. R.: Aerosol Pollution Impact on Precipitation, Springer, 386 pp., 2009.

Liu, P. S. K., Leaitch, W. R., Banic, C. M., Li, S.-M., Ngo, D., and Megaw, W. J.: Aerosol observations at Chebogue Point during the 1993 North Atlantic Regional Experiment: Relationships among cloud condensation nuclei, size distribution, and chemistry, J. Geophys. Res.-Atmos., 101(D22), 28971-28990, 1996.

Lynn, B., Khain, A. P., Rosenfeld, D., and Woodley, W.: Effects of aerosols on precipitation from orographic clouds, J. Geophys. Res.-Atmos., 112, D10225, 13 pp., doi:10.1029/2006JD007537, 2007.

Medina, J., Nenes, A., Sotiopoulou, R.-E. P., Cottrell, L. D., Ziemba, L. D., Beckman, P. J., and Griffin, R. J.: Cloud condensation nuclei closure during the International Consortium for Atmospheric Research on Transport and transformation 2004 campaign: Effects of size-resolved composition, J. Geophys. Res.Atmos., 112, D10S31, 10 pp., 2007.

Mertes, S., Schroder, F., and Wiedensohler, A.: The particle detection efficiency curve of the TSI-3010 CPC as a function of the temperature differential between saturator and condenser, Aerosol Sci. Technol., 23(2), 257-261, 1995.

Mesinger, F., DiMego, G., Kalnay, E., Mitchell, K., Shafran, P. C., Ebisuzaki, W., Jovic, D., Woollen, J., Rogers, E., Berbery, E. H., Ek, M. B., Fan, Y., Grumbine, R., Higgins, W., Li, H., Lin, Y., Manikin, G., Parrish, D., and Shi, W.: North American Regional Reanalysis, Bull. Amer. Meteor. Soc., 87(3), 343-360, 2006. 
Petters, M. D. and Kreidenweis, S. M.: A single parameter representation of hygroscopic growth and cloud condensation nucleus activity, Atmos. Chem. Phys., 7, 1961-1971, doi:10.5194/acp-71961-2007, 2007.

Petters, M. D., Prenni, A. J., Kreidenweis, S. M., and DeMott, P. J.: On measuring the critical diameter of cloud condensation nuclei using mobility selected aerosol, Aerosol Sci. Technol., 41(10), 907-913, 2007.

Politovich, M. K. and Vali, G.: Observations of liquid water in orographic clouds over Elk Mountain, J. Atmos. Sci., 40, 13001313, 1983.

Quinn, P. K., Bates, T. S., Coffman, D. J., and Covert, D. S.: Influence of particle size and chemistry on the cloud nucleating properties of aerosols, Atmos. Chem. Phys., 8, 1029-1042, doi:10.5194/acp-8-1029-2008, 2008.

Ramanathan, V., Crutzen, P., Kiehl, J., and Rosenfeld, D.: Aerosols, climate and the hydrological cycle, Science, 294, 2119-2124, 2001.

Reutter, P., Su, H., Trentmann, J., Simmel, M., Rose, D., Gunthe, S. S., Wernli, H., Andreae, M. O., and Pschl, U.: Aerosoland updraft-limited regimes of cloud droplet formation: influence of particle number, size and hygroscopicity on the activation of cloud condensation nuclei (CCN), Atmos. Chem. Phys., 9, 7067-7080, doi:10.5194/acp-9-7067-2009, 2009.

Richardson, M. S., DeMott, P. J., Kreidenweis, S. M., Cziczo, D. J., Dunlea, E. J., Jimenez, J. L., Thomson, D. S., Ashbaugh, L. L., Borys, R. D., Westphal, D. L., Casuccio, G. S., and Lersch, T. L.: Measurements of heterogeneous ice nuclei in the western United States in springtime and their relation to aerosol characteristics, J. Geophys. Res.-Atmos., 112, D02209, 16 pp., doi:10.1029/2006JD007500, 2007.

Roberts, G. C. and Nenes, A.: A continuous-flow streamwise thermal-gradient $\mathrm{CCN}$ chamber for atmospheric measurements, Aerosol Sci. Technol., 39(3), 206-221, 2005.

Rose, D., Gunthe, S. S., Mikhailov, E., Frank, G. P., Dusek, U., Andreae, M. O., and Pöschl, U.: Calibration and measurement uncertainties of a continuous-flow cloud condensation nuclei counter (DMT-CCNC): CCN activation of ammonium sulfate and sodium chloride aerosol particles in theory and experiment, Atmos. Chem. Phys., 8, 1153-1179, doi:10.5194/acp-8-11532008, 2008.

Rosenfeld, D. and Givati, A.: Evidence of orographic precipitation suppression by air pollution-induced aerosols in the western United States, J. Appl. Meteorol. Clim., 45, 893-911, 2006.

Saleeby, S. M., Cotton, W. R., Lowenthal, D., Borys, R. D., and Wetzel, M. A.: Influence of cloud condensation nuclei on orographic snowfall, J. Appl. Meteorol. Clim., 48, 903-922, doi:10.1175/2008JAMC1989.1, 2009.

Seinfeld, J. H. and Pandis, S. N.: Atmospheric Chemistry and Physics, Wiley \& Sons, Hoboken, New Jersey, 1203 pp., 2006.

Shantz, N. C., Leaitch, W. R., Phinney, L., Mozurkewich, M., and Toom-Sauntry, D.: The effect of organic compounds on the growth rate of cloud droplets in marine and forest settings, Atmos. Chem. Phys., 8, 5869-5887, doi:10.5194/acp-8-5869-2008, 2008.

Snider, J. R. and Petters, M. D.: Optical particle counter measurement of marine aerosol hygroscopic growth, Atmos. Chem. Phys., 8, 1949-1962, doi:10.5194/acp-8-1949-2008, 2008.
Snider, J. R., Guibert, S., Brenguier, J.-L., and Putaud, J.-P.: Aerosol activation in marine stratocumulus clouds: 2. Kohler and parcel theory closure studies, J. Geophys. Res.-Atmos., 108(D15), 23 pp., doi:10.1029/2002JD002692, 2003.

Snider, J. R., Petters, M. D., Wechsler, P., and Liu, P. S. K.: Supersaturation in the Wyoming CCN instrument, J. Atmos. Oceanic. Technol., 23, 1323-1339, 2006.

Snider, J. R., Wex, H., Rose, D., Kristensson, A., Stratmann, F., Hennig, T., Henning, S., Kiselev, A., Bilde, M., Burkhart, M., Dusek, U., Frank, G. P., Kiendler-Scharr, A., Mentel, T. F., Petters, M. D., and Pöschl, U.: Intercomparison of cloud condensation nuclei and hygroscopic fraction measurements: Coated soot particles investigated during the LACIS Experiment in November (LExNo), J. Geophys. Res.-Atmos., 115, D11205, doi:10.1029/2009JD012618, 2010.

Squires, P. and Twomey, S.: The relation between cloud drop numbers and the spectrum of cloud nuclei, Physics of Precipitation, Monograph, No. 5, Amer. Geophys. Union., Washington, DC, 211-219, 1961.

Stevens, B. and Feingold, G.: Untangling aerosol effects on clouds and precipitation in a buffered system, Nature, 461, 607-613, doi:10.1038/nature08281, 2009.

Stroud, C. A., Nenes, A., Jimenez, J. L., DeCarlo, P. F., Huffman, J. A., Bruintjes, R., Nemitz, E., Delia, A. E., Toohey, D. W., Guenther, A. B., and Nandi, S.: Cloud activating properties of aerosol observed during CELTIC. J. Atmos. Sci., 64, 441-460, 2007.

Twomey, S.: The nuclei of natural cloud formation, Part II: The supersaturation in natural clouds and the variation of cloud droplet concentration, Geofis. Pura. Appl., 43, 243-249, 1959.

Twomey, S.: The influence of pollution on the shortwave albedo of clouds, J. Atmos. Sci., 34, 1149-1152, 1977.

Twomey, S. and Warner, J.: Comparison of measurements of cloud droplets and cloud nuclei, J. Atmos. Sci., 24, 702-703, 1967.

U.S. Environmental Protection Agency: 2005 National Emissions Inventory Data \& Documentation, http://www.epa.gov/ttnchie1/ net/2005inventory.html, 2009.

VanReken, T. M., Rissman, T. A., Roberts, G. C., Varutbangkul, V., Jonsson, H. H., Flagan, R. C., and Seinfeld, J. H.: Toward aerosol/cloud condensation nuclei (CCN) closure during CRYSTAL-FACE, J. Geophys. Res.-Atmos., 108, 18 pp., doi:10.1029/2003JD003582, 2003.

Ward, D. S., Eidhammer, T., Cotton, W. R., and Kreidenweis, S. M.: The role of the particle size distribution in assessing aerosol composition effects on simulated droplet activation, Atmos. Chem. Phys., 10, 5435-5447, doi:10.5194/acp-10-5435-2010, 2010.

Warner, J.: A reduction of rain associated with smoke from sugarcane fires - An inadvertent weather modification, J. Appl. Meteor., 7, 247-251, 1968.

Wilks, D. S.: Statistical methods in the atmospheric sciences, 2 Edition International Geophysics Series, 59, Academic Press, 464 pp., 1995.

Zhang, X. B., Zwiers, F. W., Hegerl, G. C., Lambert, F. H., Gillet, N. P., Solomon, S., Stott, P. A., and Nozawa, T.: Detection of human influence on twentieth-century precipitation trends, Nature, 448, 461-466, 10.1038/nature06025, 2007. 